\title{
ECOLOGICAL AND TECHNOLOGYCAL ASPECTS OF ASH AND SLAG WASTES UTILIZATION
}

\author{
Tatyana Nikolaevna Aleksandrova', Stepan Alekseyevich Korchevenkov ${ }^{1}$ \\ 1 Mineral processing department, Saint-Petersburg Mining University, Vasilyevsky Island 21st line, 2, 199106 \\ Saint-Petersburg, Russia, e-mail: opiopi@spmi.ru
}

Received: 2017.05.15 Accepted: 2017.06.01 Published: 2017.07.01

\begin{abstract}
The article presents the results of investigation focused on the utilization of ash and slag wastes (ASW) in Russia including investigation of chemical and physical properties of ASW and processing products. Many factors influence the technological properties of ash and slag materials: naturals, processes and environments. The integrated treatment of ash and slag wastes of both stored and re-formed types will allow obtaining the following commercial products: coal concentrate, iron concentrate, aluminosilicate cenospheres, aluminosilicate product. In this study we have analyzed the methods for separation of ASW iron-containing part using the different types of the magnetic separation from the ash and slag material from one of the combined heat and power plant (CHPP) in the Russian Far East Federal District. The greatest interest is the dry magnetic separation with travelling electromagnetic field. The subject of research was a sample taken from one of ash dump of CHPP in the Far East. In the study iron concentrate containing $\mathrm{Fe}_{\text {total }}=64 \%$ was obtained recovery $68 \%$ in the low intensity (up to $5 \mathrm{kOe}$ ) travelling magnetic field.
\end{abstract}

Keywords: ash and slag wastes, waste management, iron concentrate, magnetic separation

\section{INTRODUCTION}

ASW generated when burning coal in the furnaces of CHPPs and boiler-houses are the mechanical mixture of ash and slag. Averaged yield of ash and slag is $4: 1$. Thus, the ash is a product of burning the fuel that carries over with the flue gases from the furnace of the boiler and is caught by fly-ash collectors. The slag is the material which accumulates during the fuel combustion in the slag bathes. The ash is mainly represented by the fraction of $0.01-0.1 \mathrm{~mm}$ when the maximum particle size is no more than $1-2 \mathrm{~mm}$. The slag is mainly represented by fractions of $0.1-20 \mathrm{~mm}$ when the maximum particle size is $40-60 \mathrm{~mm}$ and the minimum is $0.04 \mathrm{~mm}$. The ash is the fine mineral powder (Fig. 1) of light gray to dark gray color; the slag has the similar color, but differs from the ash of larger particle size [Melentev 1985].
By chemical composition the ash-and-slag materials mainly belong to the acidic particles. The basic mass (96-98\%) of ASW is the sum of the oxides comprising: silicon oxide $-45-60 \%$; calcium oxide $-2.5-9.6 \%$; the magnesium oxide $-0.5-4.8 \%$; iron oxide $-4.1-10.6 \%$; aluminium oxide $-10.1-21.8 \%$ and sulfur trioxide $-0.03-2.7 \%$ [Melentev 1985].

ASW are the objects for integrated treatment that is the critical task for technologists, environmental engineers and other industry professionals, as the ash and slag wastes are often accumulated within the boundaries of settlements and consist of fly ash and slag. The fly ash (hereinafter referred to as the "ash") is the fine material consisting as usual of particles with a size from fractions of micron to $0.14 \mathrm{~mm}$. The ash is formed by the combustion of solid fuels at CHPP and is caught by electrostatic precipitators, and then in the dry condition is collected 

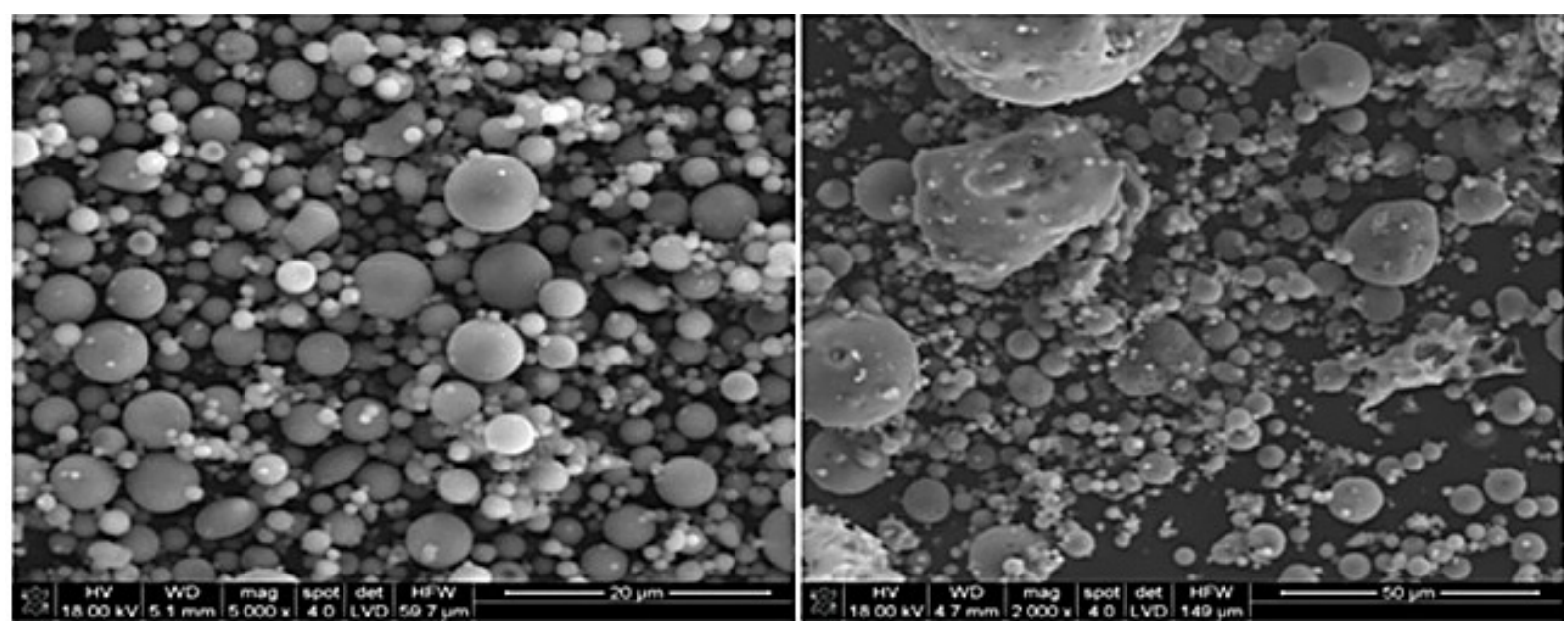

Figure 1. Scanning electron microscope images of ASW

by using the fly-ash collector for production needs; or together with the water and the slag is supplied to the ash-disposal area [Butlera et al. 1986, Ahmaruzzaman 2010].

The ash and slag waste using in the national economy plays an important role in scientific and industrial developments. The need for their involvement in the industrial processing is obvious; however, a variety of chemical and material composition of the ash-and-slag dumps as to the main components and impurity elements demonstrates the need for an integrated approach to the study of such unconventional materials. Technological properties of ash and slag materials are determined by the following factors:

- features of the coal-bearing layer formation (natural factors);

- features of the process for solid fuel burning, ash handling and dust collection (process factors);

- features of the ash and slag wastes storage (environmental factors).

A significant contribution to the instability of the material composition of ash and slag dumps makes the presence of unburned coal, the socalled unburned carbon. The amount of the unburned carbon in ashes varies widely, averaging $10-15 \%$ of the mass of the ash disposal. It is fully or partially unburned coal of different sizes. The amount of carbon loss depends on the furnace operation stability, temperature, gas phase composition and dust removal. It is well known that the combustion process is an intensive decomposition of the organic matter, accompanied by the disappearance and formation of new phases. The phase formation processes occur in solid, gaseous and liquid phases, i.e. they are heteropolar, and the interaction of these processes is so great, and the number of influencing factors is also significant, that it is almost impossible to predict effectively the composition of the combustion end products. It is known that up to $97 \%$ of ash materials are the oxides of silicon, aluminum, calcium, magnesium, iron and the other impurities are $3 \%$. These data are correct for the ashes obtained by the complete combustion of the coal. In practice, this ratio is most often violated. Additionally, the composition of ash varies depending on the method of precipitation and removal of ash from the reaction zone and transportation to the disposal site. Currently, the removal of the ash is performed mainly using the wet method that on the one hand contributes to the hardening of the major phases and, on the other hand, to the development of the leaching of certain phases formed during combustion [Aleksandrova et al. 2010, Aleksandrova 2008]

At the moment, the fly ash from none of 172 coal-fired power plants in Russian Federation, producing more than 100,000 tons of ASW per year and positioning themselves as potential suppliers of the fly ash to the Russian market, does meets the requirements of GOST 25818-91, Fly Ash of CHPPs for Concrete; Specifications. [Kalachev 2014]

Obtaining additional competitive raw materials for ferrous and non-ferrous metallurgy from ash and slag will reduce the resource intensity of production, decrease emissions, comply with environmental regulations and implement the advanced low and non-waste technologies [Sizyakov et al. 2016]. 
The integrated treatment of ash and slag wastes of both stored and re-formed types will allow obtaining the following commercial products:

- coal concentrate;

- iron concentrate and magnetite powder for ferrous metallurgy and coal mining industry;

- aluminosilicate cenospheres, the unique innovative product for the construction, oil and gas and chemical industry;

- aluminosilicate product for the construction industry and in the future for the aluminum industry;

- associated concentrates of precious and rare earth metals.

At present, there is the developed and partially tested in industry technology for the ASW treatment to obtain the iron-containing concentrate, aluminosilicate product and with the associated extraction of precious and rare metals. The flow diagram for one of possible variants of the ash treatment from Ekibastuz coal is represented in Figure 2 [Delitsyn et al. 2013].
The scheme for the ash treatment proposed by Delitsyn provides for production of belite sludge - raw material for manufacturing Portland cement clinker and other construction materials, the alumina, the expensive and critical raw material for the aluminium production, the iron concentrate that can be used in metallurgy and other industries, the carbon concentrate, which can be returned to the boiler for combustion to reduce thereby losses due to incomplete combustion. The first stage of the ash treatment (processing by physical methods) is assumed to have the dehydration, classification, which is necessary for separating coarse particles, hindering the subsequent enrichment processes. Removal of iron impurities may be performed by magnetic separation.

Therefore, from the ash of Kashirskaya SDPP containing about $8 \%$ of the total iron, for one stage the "magnetic fraction" containing $55.9 \%$ of total iron was obtained while extracting more than $52 \%$. To extract carbon from the ash of Kashirskaya SDPP the method of flotation was used. As a result of flotation it is pos-

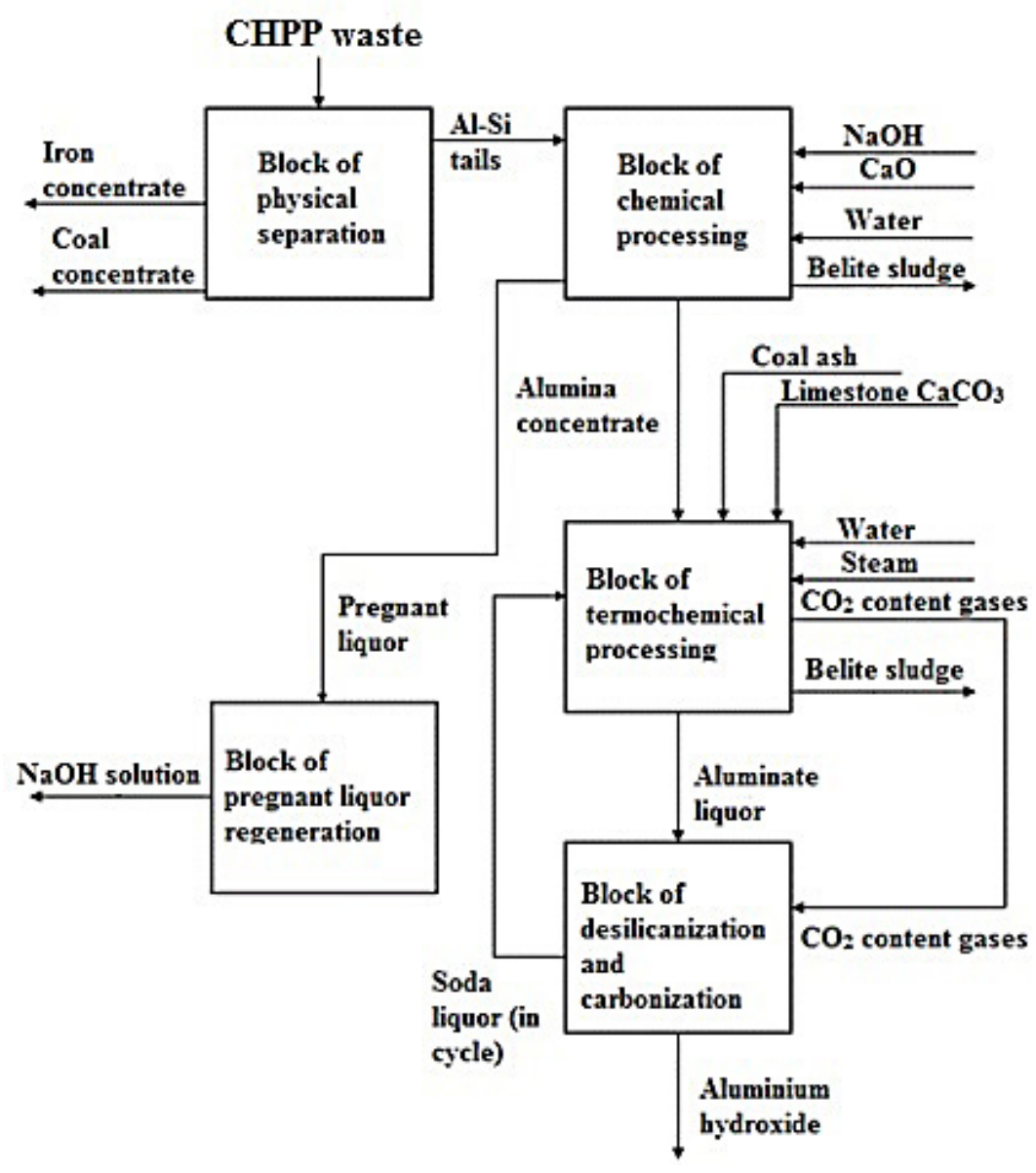

Figure 2. Block flow sheet of ASW processing 
sible to obtain carbon concentrate containing $50-65 \%$ carbon and flotation tail aluminosilicate (alumina) product with a content of $3-5 \%$ carbon that is acceptable for further thermochemical processing and production of materials for the construction industry.

Semi-industrial installation for the production of iron concentrate and aluminosilicate product is tested at CHPP-9 "Irkutskenergo"; the process flow diagram is given in Figure 3 [Prokopiev et al. 2015].

The CHPP's current ash and slag waste material is supplied to the semi-industrial installation. This material is subjected to scrubbing and screening on arc screens in the size class of 1 $\mathrm{mm}$ (to remove debris and large pieces of slag). Undersize screening product with the help of sand pump is fed into the operation of the classification in hydrocyclones. Drain from hydrocyclones is supplied into circulation and sands (the condensed product) by gravity enter into the operation of the spiral separation taking place in three stages: rougher, scavenger and cleaning spiral separation. The result of the screw separation is the tailings comprising mainly the alumosilicates and iron-bearing concentrate sent for further processing. Spiral and magnetic separation processes is represented in Figure 4.
As you can see from the represented material, the unit of the physical separation, including gravity and magnetic separation is very important when solving a problem of the ash and slag waste treatment. The greatest interest is the magnetic separation, since this process is applicable both for the pulp and dry material.

The research carried out in Poland let the implementation of technology production of iron oxides concentrate. Through coals selection, combustion process and ashes segregations the method of ferromagnetic fraction extraction from the fly ashes was developed [Hycnar et al. 2012].

\section{METHODOLOGY AND CHARACTERISTICS OF THE SUBJECT OF RESEARH}

In our study we have attempted to analyze the methods for separation of ASW iron-containing part using different types of the magnetic separation from the ash and slag material from one of CHPP in the Russian Far East Federal District.

The subject of research was a sample taken from one of ash dump of CHPP in the Far East, with the particle size of $-0.1+0.0 \mathrm{~mm}$, with the content of class $-0.074+0.0 \mathrm{~mm}-80 \%$. The average chemical composition is given in Table 1 .

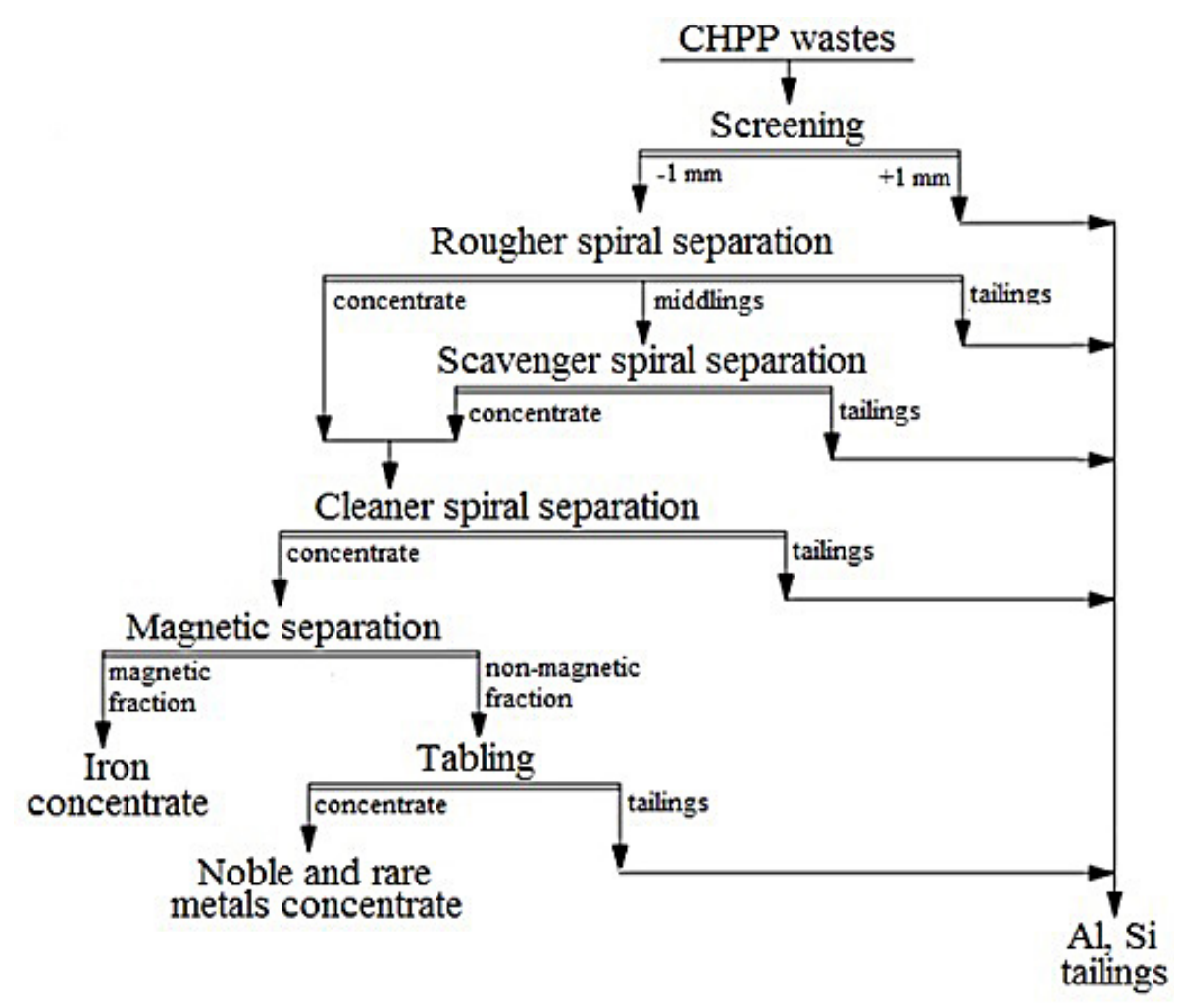

Figure 3. The "Irkutskenergo" pilot scale of ASW processing flow sheet 

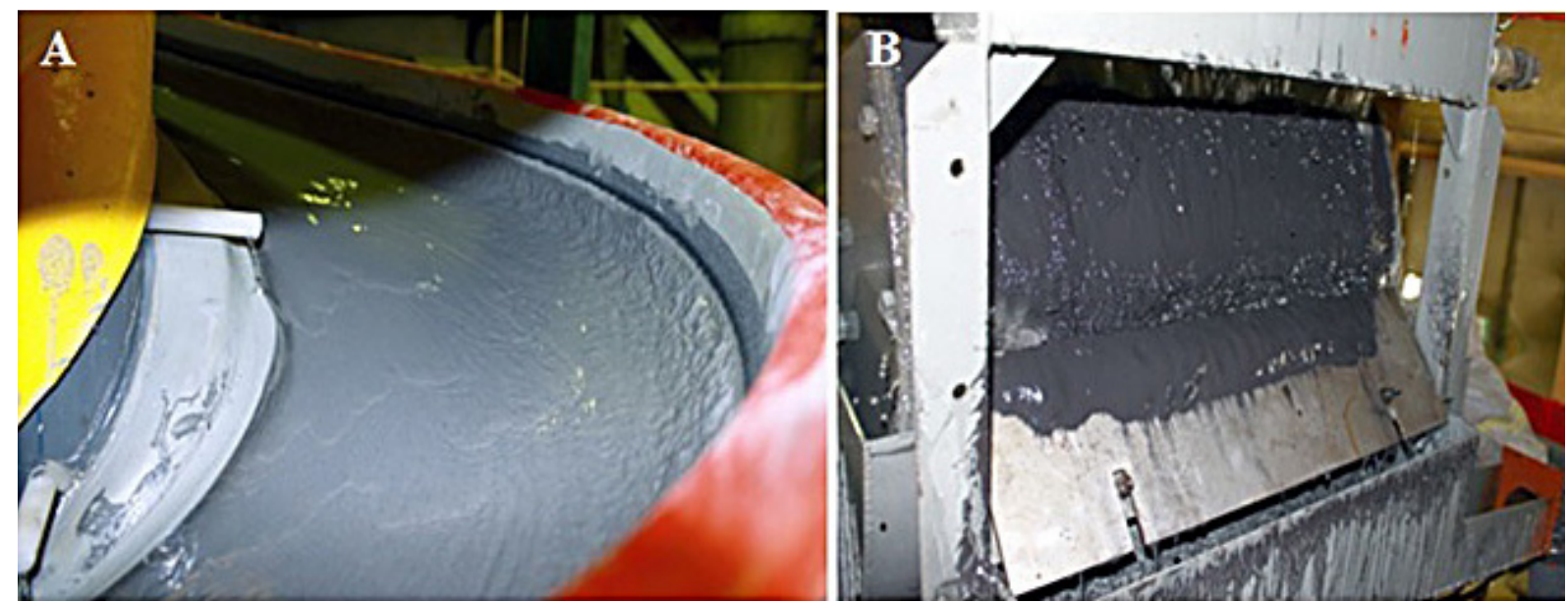

Figure 4. A - spiral process, B - magnetic separation process on the pilot scale

Table 1. - Average chemical composition of ASW sample

\begin{tabular}{|c|c|c|c|c|c|c|c|c|c|c|c|c|}
\hline Element: & $\mathrm{SiO}_{2}$ & $\mathrm{TiO}_{2}$ & $\mathrm{Al}_{2} \mathrm{O}_{3}$ & $\mathrm{Fe}_{2} \mathrm{O}_{3}$ & $\mathrm{MnO}$ & $\mathrm{CaO}$ & $\mathrm{MgO}$ & $\mathrm{Na}_{2} \mathrm{O}$ & $\mathrm{K}_{2} \mathrm{O}$ & $\mathrm{P}_{2} \mathrm{O}_{5}$ & Others & Total: \\
\hline Content, $\%$ & 54,79 & 0,76 & 20,71 & 13,1 & 0,06 & 3,9 & 1,11 & 0,75 & 1,75 & 0,13 & 3 & 100 \\
\hline
\end{tabular}

The study of the material composition of the sample is made by the standard method with the use of the screen, chemical and microscopic analyses. Microscopic analysis of the separation products is performed using the microscope Carl Zeiss AXIO Lab.A1.

Part of the process sample was subjected to standard magnetic analysis with Davis tube. A Davis tube (DT) is a laboratory instrument designed to separate small samples of magnetic ores into strongly magnetic and weakly magnetic fractions. It has become standard laboratory equipment used for the assessment of the separability of magnetic ores by low-intensity magnetic separators [Schulz N.F. 1964].

Experiments were performed for the magnetic separation in the air with the laboratory separator EVS 10/5 (NPK Mekhanobr Tekhnika) and the new experimental installation of travelling magnetic field; the scheme of installation is represented in Figure 5.

The feature of the travelling magnetic field is the rotation of the magnetic induction vector at each point of working space of the magnetic separator (Fig. 6). Strictly speaking, all drum and belt separators with alternating polarity of poles on the path of enriching material can be called as separators with the travelling magnetic field. The magnetic separation in the travelling fields is a highly effective process that allows obtaining the magnetic fractions of very high quality, thanks to the active magnetic mixing of the enriching material.
We have performed the comparison and analysis of data on previously conducted studies for obtaining the magnetic fraction of ash dumps at CHPP in Far East with the help of various types of

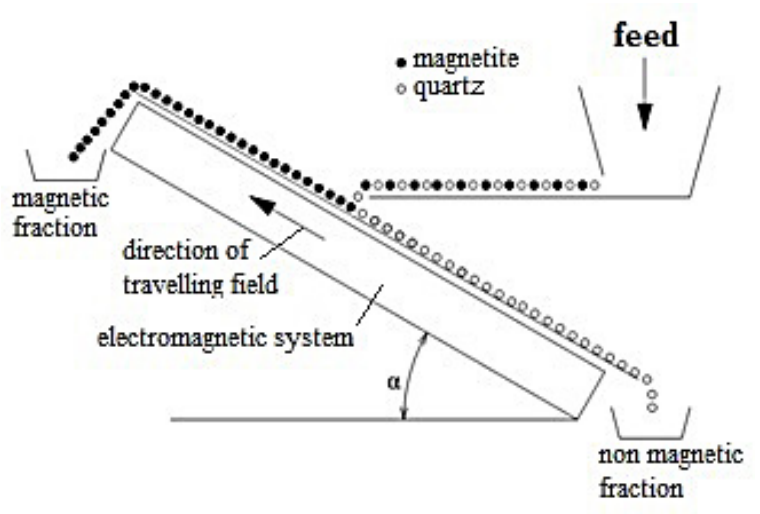

Figure 5. Scheme of travelling magnetic field installation

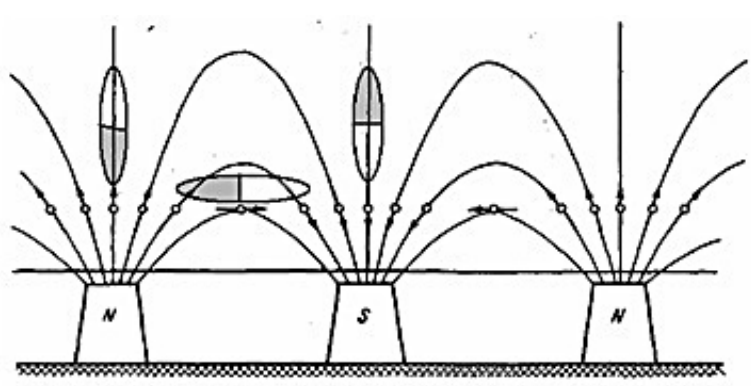

Figure 6. Scheme of the magnetic induction vector rotation and travelling magnetic field generation 
laboratory magnetic separators, namely: Outotec Slon 100, EBM 32/20. This high gradient magnetic separator Outotec Slon 100 has a number of advantages: high efficiency in the enrichment of fine material due to the vertical design of the separator, the mechanism creating the pulsation and the core matrix of the separator (Fig. 7). The fine non-magnetic particle catching is minimized by the arrangement of the matrix and the mechanism of pulsation [Dobbins M. et al. 2010].

\section{RESULTS}

The results of standard magnetic analysis with Davis tube are given in Table 2, magnetic separation performance curves for ASW material is presented in Figure 8

From these data we can conclude about the possibility of iron extraction at the level of $65-68 \%$ with the obtaining the iron concentrate containing Fetotal $=40 \%$ in magnetic field intensity up to $5 \mathrm{kOe}$.

As confirmed by the practice of the wet magnetic enrichment of ash and slag dumps (Table 3), the obtaining of higher-quality iron concentrates is complicated by the low selectivity of the process of magnetic separation in the constant fields with various intensities. The results of earlier studies for extracting the magnetic fraction from the same material of the ash and slag dumps with a wet high-gradient magnetic separator Outotec Slon 100 were compared with the data obtained using the wet electromagnetic drum separator EBM 32/20 [Alexandrova et. al. 2015, Prokhorov 2015].

The represented data fully confirm the results of the magnetic analysis.

The main disadvantage from an environmental point of view is the separating medium, namely water. Therefore, the greatest interest is the

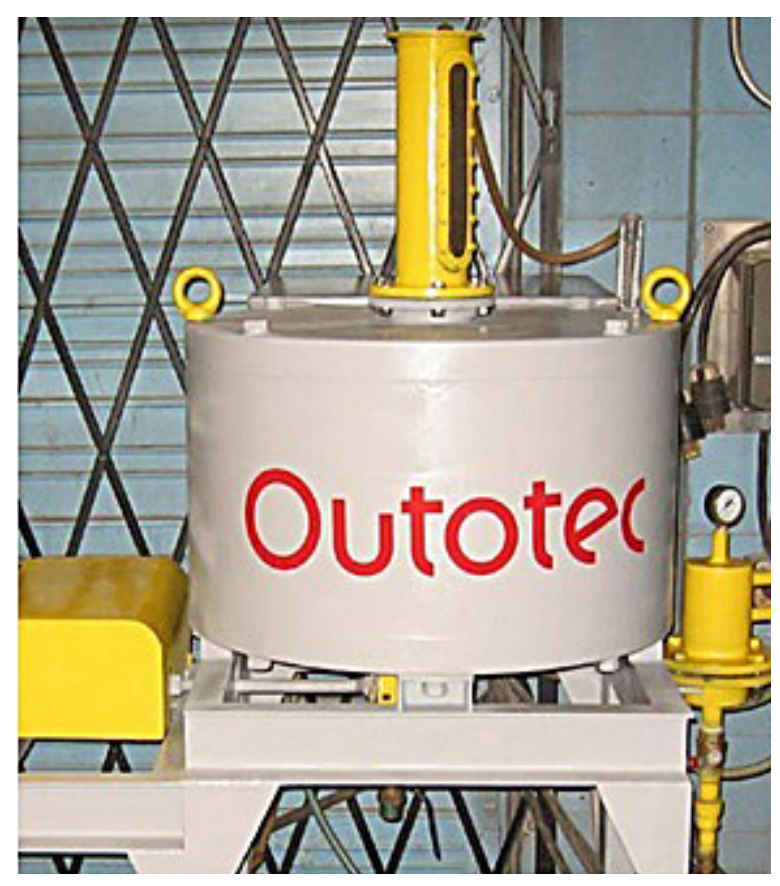

Figure 7. Outotec Slon 100 laboratory magnetic separator

magnetic separation in the air medium. However, if we consider the modern market of the magnetic separators, we can state the lack of samples suitable for separation in the magnetic field of such fine particles as the ash. Therefore, we have attempted to extract the magnetic product from the sample of ash and slag dumps using the dry method with the separators: EVS 10/5 (electromagnetic roll-type magnetic separator, Mekhanobr-Tekhnika) (Fig. 9, 10) and experimental installation with travelling field. The results of the separation are given in Table 4.

As you can see from the represented diagram, obtaining higher-quality iron concentrate is complicated. The results of dry magnetic separation in permanent magnetic fields with different intensity confirm the need to search more selectivity magnetic separation process. A possible solution is the separation in the travelling fields.

Table 2. The results of Davis tube magnetic assay

\begin{tabular}{|l|c|c|c|c|}
\hline \multicolumn{1}{|c|}{ Parameters } & Intensity, Oe & Yield, $\%$ & Iron content, \% & Iron recovery, $\%$ \\
\hline Magnetic fraction 1 & 795 & 0.89 & 50.8 & 5.4 \\
\hline Magnetic fraction 2 & 1640 & 4.26 & 45 & 22.8 \\
\hline Magnetic fraction 3 & 2435 & 5.58 & 44 & 29.2 \\
\hline Magnetic fraction 4 & 3220 & 1.04 & 32 & 3.9 \\
\hline Magnetic fraction 5 & 3925 & 1.55 & 20.7 & 3.8 \\
\hline Magnetic fraction 6 & 4515 & 1.51 & 15.5 & 2.8 \\
\hline Non-magnetic fraction & & 85.18 & 3.2 & 32.4 \\
\hline ASW sample & & 100.00 & 8.4 & 100 \\
\hline
\end{tabular}




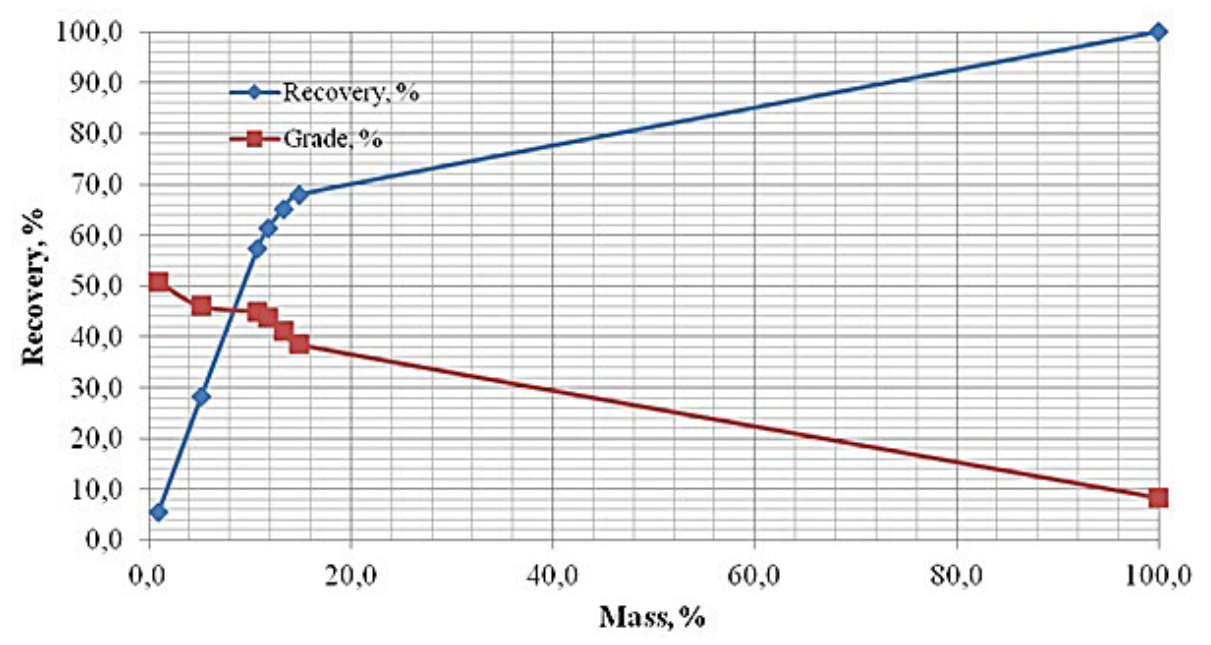

Figure 8. Separation performance curves

Table 3. The results of magnetic separation in different type separators

\begin{tabular}{|l|c|c|}
\hline \multicolumn{1}{|c|}{ Parameters } & Slon 100 & EBM 32/20 \\
\hline Iron recovery to concentrate, $\%$ & 39.26 & 36.19 \\
\hline Fe content in concentrate, \% & 43.68 & 43.06 \\
\hline Yield of concentrate, \% & 6.47 & 3.2 \\
\hline Fe content in feed, \% & 7.45 & 3.81 \\
\hline
\end{tabular}

The magnetic and non-magnetic products obtained in the course of the travelling magnetic field separation is typically for ash spheres with different iron content (Fig. 11).

From table 4 data we can conclude about the possibility of high recovery level cleaning operation with obtaining saleable iron concentrate. This concentrate can be used for ferrous metallurgy.

Further use of tailings of the dry magnetic separation is possible in the construction and production of building materials. Both dry and wet (from the dumps) dispersed ash of CHPP is widely used for manufacturing the products of dense or porous ash concrete (wall blocks and panels, plates of coverings and floor). In China the designers are developing the technology for the advanced processing of ASW, namely, for obtaining the products for water purification - zeolites. Also it is possible to perform the extraction of aluminium containing components, under-fired coal and particles of rare and precious metals (Fig. 12). [Shabarov A.N. et al. 2016].

Interesting are also the experiences of Rock Tron company which manufactures spherical magnetites called MagTron ${ }^{\mathrm{TM}}$, which are assigned to not only to heavy liquid preparation but the production of insulation as well [Short G. 2010.].

\section{COCLUSIONS}

The problem of shortage of mineral raw materials makes it relevant to search for additional sources. Great potential in addressing this problem lies in the possible involvement in development of technogenic deposits - accumulations of

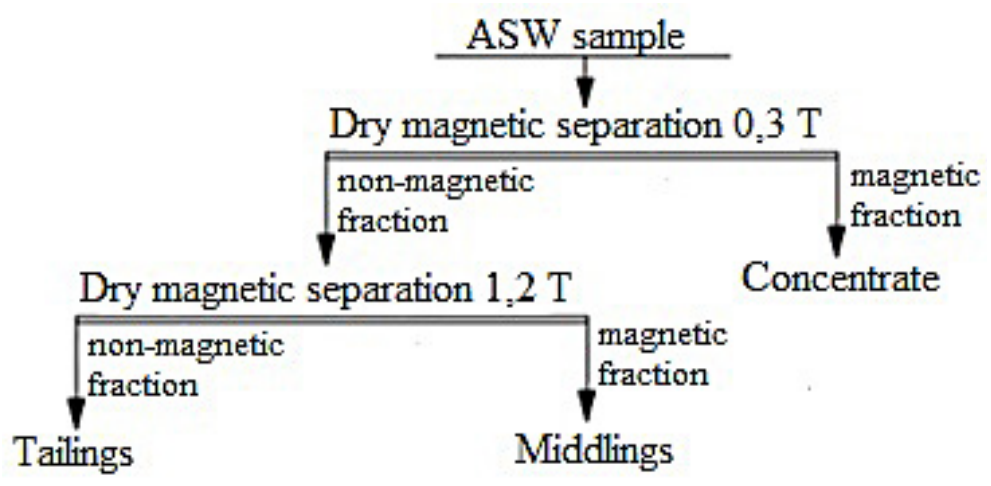

Figure 9. EVS 10/5 test principle flow sheet 


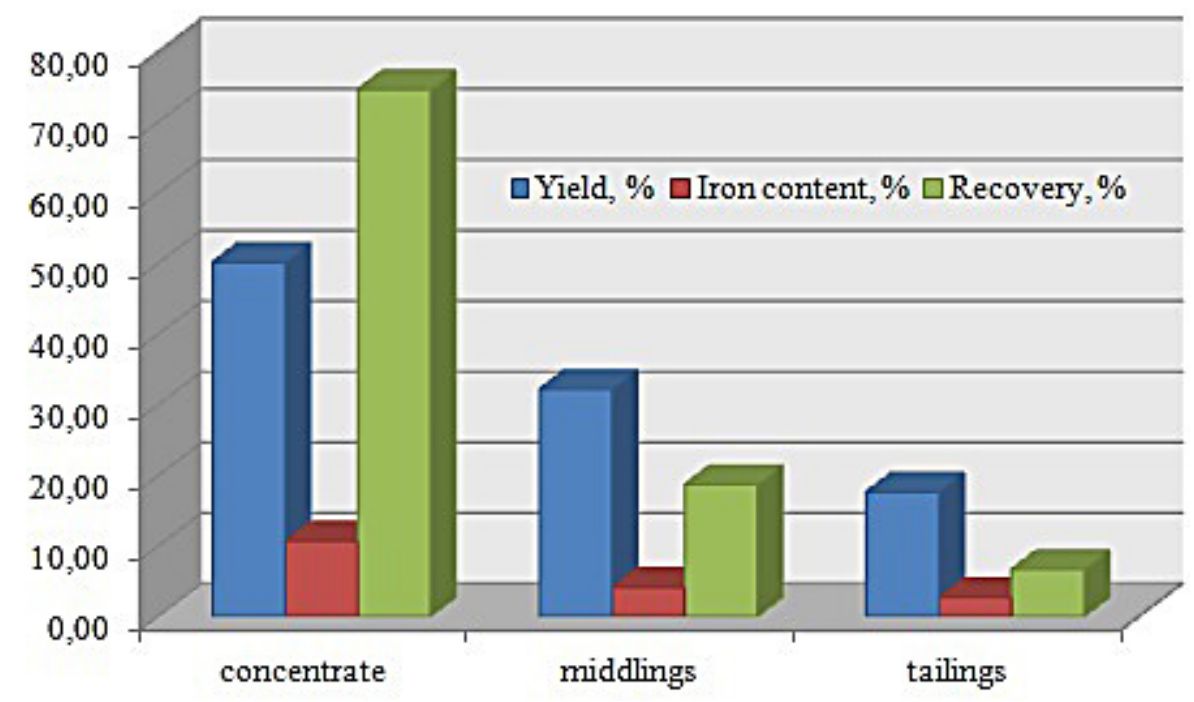

Figure 10. The diagram of results EVS 10/5 test

Table 4. The results of the travelling magnetic field separation test

\begin{tabular}{|l|c|c|c|c|}
\hline \multirow{2}{*}{ Product name } & \multirow{2}{*}{ Yield, $\%$} & \multicolumn{2}{c|}{ Content, \% } & \multirow{2}{*}{ Iron recovery, \% } \\
\cline { 3 - 5 } & & $\mathrm{Fe}_{\text {total }}$ & $\mathrm{SiO}_{2}$ & \\
\hline \multicolumn{3}{|c|}{ Travelling magnetic field separation $(50 \mathrm{~Hz}, 50 \mathrm{mT})$} \\
\hline Magnetic fraction 1 & 12,96 & 42,9 & 23,6 & 51,2 \\
\hline Non-magnetic fraction 1 & 87,04 & 6,1 & 65,7 & 48,8 \\
\hline Feed ASW & 100 & 10,9 & 60,30 & 100 \\
\hline \multicolumn{5}{|c|}{ Travelling magnetic field cleaning separation } \\
\hline Magnetic fraction 2 & 8,20 & 61,2 & 6,2 & 46,17 \\
\hline Non-magnetic fraction 2 & 4,76 & 11,4 & 53,6 & 4,99 \\
\hline Feed (magnetic fraction 1) & 12,96 & 42,90 & 23,60 & 51,2 \\
\hline
\end{tabular}
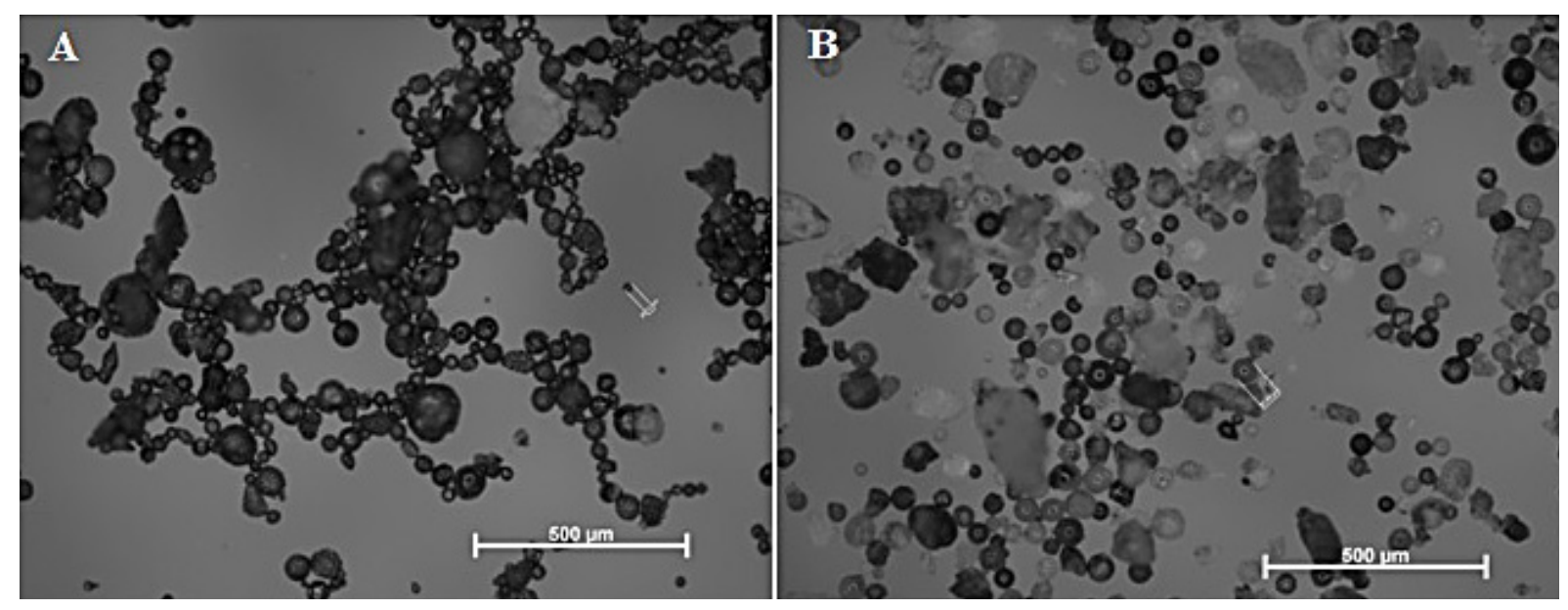

Figure 11. A - magnetic fraction, $\mathrm{B}$ - non-magnetic fraction 

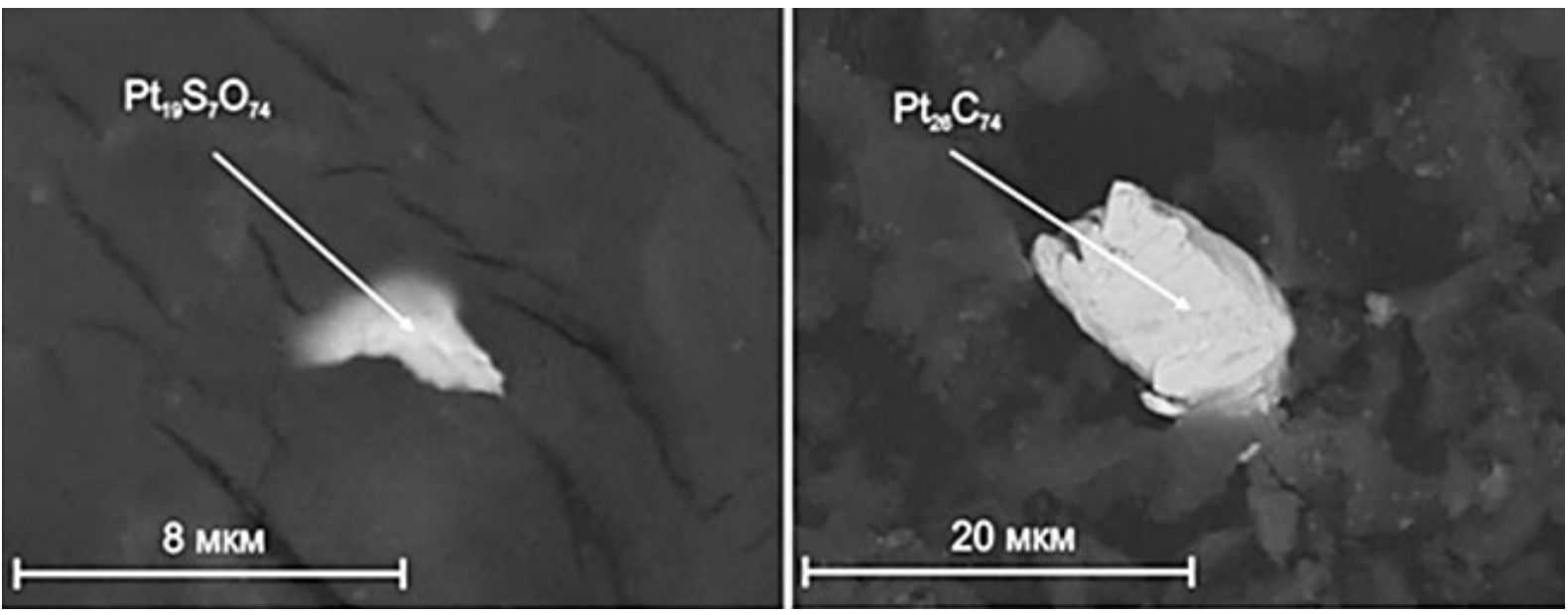

Figure 12. Scanning electron microscope images of precious particles in ASW material

minerals on the surface of the Earth or in mines, which are the wastes of mining, concentration, metallurgical and other industries and which are suitable in quantity and quality for industrial use, that becomes possible with the development of their processing technology and changes in economic conditions.

In our country there is accumulated a huge amount of various types of industrial wastes generated by mining and metallurgical complexes. Often, these wastes contain valuable components that can be removed obtaining the additional products. In addition, processing of industrial waste solves the major environmental problem.

The use of wastes from the mining and industrial production as the secondary mineral resources is the most important provision of rational use of raw materials in the following areas:

- improved provision level of national economy for mineral resources, due to the processing of minerals accompanying the primary natural resources with the use of wastes of the current output;

- significant savings in capital investments and lower production costs at the enterprises with processing the wastes;

- significant savings, due to the geological exploration works, as the secondary mineral resources are already mined raw materials;

- improved economic indicators of production, including the cost of products and profitability of the primary production;

- ecological, economic and social effects.

The possibility and desirability of extraction of iron concentrate from ASW was positively verified. Now, when we have access to dry and wet, highly efficient magnetite separators, and there is a strong demand for iron-bearing highly-disintegrated materials, there are conditions to the wide dissemination of the process of ASW separation.

\section{Acknowledgements}

The research was carried out under the grant received from Russian Foundation of Fundamental Research № 16-05-00460/16.

\section{REFERENCES}

1. Ahmaruzzaman M. A. 2010. Review on the utilization of fly ash. Progress in Energy and Combustion Science, 36 (3), 327-363.

2. Aleksandrova T.N. 2008. Development of estimation and management methods environmental technological systems for ore and placer gold mining with waste treatment in the Far Eastern region of Russia. Ph.D. Thesis, Transbaikal State University, Khabarovsk.

3. Aleksandrova T.N., Krupskaja L.T., Lipina L.N. 2010. Estimation of influence of natural-mining systems at ore gold mining on environment. Mining information and analytical bulletin, 6, 286-292.

4. Alexandrova T.N., Prokhorov K.V., Lvov V.V. 2015. Recovery of magnetic fraction from coal combustion waste by high-gradient magnetic separation. Mining Journal, 12, 4-8.

5. Butlera W.B., Mearinga M.A. 1986. Fly ash beneficiation and utilization in theory and in practice. Proc. Materials Research Society Symposia, 65, 11-17.

6. Delitsyn L.M. et. al. 2013. The complex processing of coal ash power plants in the Russian Federation. Proc. X CIS Congress of the Mineral Processing Engineers, 1, 225-230. 
7. Dobbins M., Dunn P., Sherrell I. 2010. Recent advances in magnetic separator designs and applications. Tsvetnye Metally, 2, 48-54.

8. Hycnar J.J., Kochański B., Tora B. 2012. Manufacture and properties of magnetite dust from coal combustion products. Proc. IV Conference «Ashes from TPPs: removal, transport, processing, storage», 192-196.

9. Kalachev A.I. 2014. The ash and slag waste market of Russia through the eyes of trader. Phoenix consortium. Proc. V Conference «Ashes from TPPs: removal, transport, processing, storage», 41-46.

10. Melentev V.A. 1985. The composition and properties of ash and slag TPP. Energoatomisdat, Leningrad.

11. Prokhorov K.V. 2015. Development of the valuable components recovery technology from ASW (example CHPP "Khabarovskenergo"). Ph.D. Thesis, Irkutsk National Research Technical University, Irkutsk.
12. Prokopiev S.A. et al. 2015. The research of possibility of obtaining quality iron concentrate and other valuable components from ash TTP-9 «Irkutscenergo». Proc. X CIS Congress of the Mineral Processing Engineers, 1, 256-261.

13. Schulz N.F. 1964. Determination of the magnetic separation characteristics with the Davis Magnetic Tube. Trans. SME-AIME, 229, 211-216.

14. Shabarov A.N., Alexandrova T.N., Nikolaeva N.V. 2016. To the question of complex use of ashes and slag waste CHP plant. Proc. XVIII International Coal Preparation Congress, 1, 603-607.

15. Short G. 2010. Rising from the ashes (Short Survey). Chemical Engineer, 827, 40-41.

16. Sizyakov V.M., Vlasov A.A., Bazhin V.Yu. 2016. Strategy tasks of the Russian metallurgical complex. Tsvetnye Metally, 1, 32-37. 